Editorial

\title{
Beyond Mainstream Media and Communication Perspectives on the Arab Uprisings
}

\author{
Hanan Badr ${ }^{1, *}$ and Lena-Maria Möller ${ }^{2}$ \\ ${ }^{1}$ Department of Mass Communication and Media, Gulf University for Science and Technology, Kuwait; \\ E-Mail: badrh@gust.edu.kw \\ 2 Max Planck Institute for Comparative and International Private Law, Germany; E-Mail: moeller@mpipriv.de \\ * Corresponding author
}

Submitted: 29 November 2021 | Published: 17 December 2021

\begin{abstract}
This editorial argues for more research connecting media and communication as a discipline and the Arab Uprisings that goes beyond the mainstream techno-deterministic perceptions. The contributions in this thematic issue can be summarized around three central arguments: First, mainstream media, like TV and journalism, are central and relevant actors in the post-Arab Uprisings phase which have often been overlooked in previous literature. Second, marginalized actors are still engaged in asymmetric power struggles due to their vulnerable status, the precarious political economy, or a marginalized geographic location outside centralized polities. Finally, the third strand of argument is the innovative transnational geographic and chronological synapses that studying media and Arab Uprisings can bring. The editorial calls for more critical and interdisciplinary approaches that follow a region marked by inherent instability and uncertainty.
\end{abstract}

\section{Keywords}

Arab Uprisings; critical research; interdisciplinary; journalism; media asymmetries; power dynamics; transnational comparison

\section{Issue}

This editorial is part of the issue "Ten Years after the Arab Uprisings: Beyond Media and Liberation," edited by Hanan Badr (Gulf University for Science and Technology, Kuwait) and Lena-Maria Möller (Max Planck Institute for Comparative and International Private Law, Germany).

(C) 2021 by the authors; licensee Cogitatio (Lisbon, Portugal). This editorial is licensed under a Creative Commons Attribution 4.0 International License (CC BY).

\section{Introduction}

Initial research on media and communication and the Arab Uprisings, a wave that quickly subdued in our discipline, highlighted the connection between (social) media and mobilization, attributing digital media a central role in the public's empowerment. Unlike other disciplines, such as political studies and anthropology or Middle East studies, what happened after the initial mobilization moment remained unaddressed from a media and communication studies perspective. However, media have been crucial during the disruptive and self-reflective processes in this turbulent decade of political, social, and cultural upheaval. In this thematic issue, we investigate what happened after the initial moment of mobilization. We want to provide scholarship that does not reconstruct the Arab Uprisings from a predominantly Euro- and US-centric theoretical perspective that puts democratization, security concerns, and economic consequences in the foreground, without critique and contextualization.

Therefore, we are particularly proud that the thematic issue introduces fresh perspectives on the Arab Uprisings that go beyond the binary of romanticized or gloomy depictions: Instead of reducing the Arab Uprisings to a moment of disruption for activism, media, and politics, the contributions nuance the societal, cultural, and political interdependencies, beyond technodeterministic logics acknowledging the process character. We are glad that the thematic issue brings 
together several intersections of geographic peripheries in Tunisia, gender marginalization in Palestine, and progressive journalists in highly constrained contexts in Egypt. The contributions retrace the interactions and negotiation processes between media, society, and politics across the chronological arc of 10 years. The selected articles uncover several terrains of media interaction with politics, societies, and histories in the Arab countries ranging from Tunisia, Syria, Lebanon, Egypt, and Palestine. They also investigate regional, transnational consequences in neighboring non-Arab countries such as Turkey. We would have liked to receive contributions on the second wave of the Arab Uprisings in Sudan, Algeria, Iraq, or Lebanon: protest waves that remind us that the so-called stability of the Arab region is fragile and not always sustainable.

The contributions express three central arguments that are innovative and multi-faceted: First, journalists are still central and relevant actors in the post-Arab Uprisings phase that show nuanced struggles often overlooked in previous studies. Second, marginalized actors are still engaged in asymmetric power struggles due to their vulnerable status as refugees, the precarious political economy, or the marginalized geographic locations. Finally, the third strand of argument highlights the innovative transnational geographic and chronological synapses that studying media and Arab Uprisings can bring.

\section{Traditional Media and Journalism Still Matter in the Post-Arab Uprisings Phase}

The contributions in this thematic issue show how diverse and rich the scholarly interpretation of media and Arab Uprisings can become when we move beyond the over-researched and simplistic media-mobilization analysis. Some contributions highlight the ongoing negotiation processes in professional journalism amid constraining and fragmenting shifts in the media spheres. Journalists as actors are a common theme in this thematic issue, where some contributions investigate patterns of agency of professional and non-professional media actors. Yazan Badran (2021) argues in his article "Understanding Emerging Media: Voice, Agency, and Precarity in the Post-2011 Arab Mediasphere" that several emerging Arab media organizations in Egypt, Syria, and Tunisia represent specific interventions into the politics of voice in their respective national and local contexts. A critical perspective on the political economy questions the precarity and complex interactions between political and professional agency in terms of voice (actors, issues, discourses) and modalities of voice (organizational models, values, and production value). Another contribution advances our understanding of how progressive media has engaged with, reconsidered, and re-articulated voices amid a turbulent transformation beyond the mobilization moment. In her case study on "A Case Study: Mada Masr-A Progressive Voice in
Egypt and Beyond," Nadia Leihs (2021) articulates that the Egyptian political context forces journalists to adapt to their surroundings, as was clear during the turbulent transformation path from 2011 until 2015. Through qualitative interviews, she concludes that Mada Masr had offered a new model that struggles to stay and make use of a new space of expression despite the constrained political framework. Leihs details how Mada Masr implements innovative ways of producing content, securing funds, and reaching out to its readers as a community.

Connecting media studies, audience studies, and social psychology, Claudia Kozman et al. (2021) offer in their contribution a comprehensive cross-sectional survey of displaced and non-displaced Syrians living in four countries: Syria, Lebanon, Jordan, and Turkey. Examining the uncertainty reduction theory during war, the study assessed people's emotions and their media use patterns as methods for reducing uncertainty to cope with the stressful situation under which they found themselves during the Syrian civil war. Connecting the Syrians' exposure to legacy media, social media, and interpersonal communication and their feelings of uncertainty and anxiety shows the primacy of TV during the crisis (and establishes a relationship between exposure to this dominant legacy medium and the tendency of audiences who gain a sense of certainty from TV content and post more on social media.) This finding is tightly related to legacy media consumption, further signaling the role traditional television still plays in people's lives during uncertain times.

\section{Marginalized Struggles in Asymmetric Power Dynamics}

Another strand of the contribution goes beyond classic phenomena to highlight marginalized actors caught in asymmetric power struggles. Noah Bassil and Nourhan Kassem (2021) followed the ebb and flow of the vibrant post-2011 local media scene in Tunisia. In a centralized, tightly controlled country under Ben Ali before 2011, the flourishing of local media in the provinces increased pluralism, freedom, and participation, allowing the expression of the voices and grievances of Tunisians outside the capital. In this contribution, the authors do not replicate the euphoric Tunisian exception hypothesis; they nuance the dilemmas and trajectories of a comprehensive overview of local media that challenge the strong oligarchic centralization of the media in Tunisia. The authors argue that local media have the potential to empower local communities and promote democratization from below, but they face structural and political challenges in the fields of independent political economy and viable business models.

Another contribution that sheds light on the everyday grievances of the people and clashing public perceptions of governmental projects is offered by Hassan Elmouelhi et al.'s (2021) article "Mediatizing Slum Relocation in Egypt: Between Legitimization and 
Stigmatization." By investigating two media-prominent slum relocation projects Al-Max and Al-Asmarat, the article shows the contrasting media portrayals in mainstream and social media. The article argues that the state narrative legitimized its rule by mediating urban development as a human right to live in dignity and have a clean, safe environment. The public expressions rather focused on the need for participatory self-determination and to avoid the state imposing a stigmatization narrative on the relocated inhabitants.

One central endeavor of this thematic issue was not to replicate the hypothesis of a Facebook revolution. Indeed, Maya de Vries Kedem and Maya Majlaton (2021) show in their article "The Voice of Silence: Patterns of Digital Participation Among Palestinian Women in East Jerusalem" how Palestinian women in the distinctive occupied context of East Jerusalem chose avoidance instead of defiance in their Facebook use. Multiple layers pushed them towards digital silence: state control, kinship control, and self-control shaped their digital participation and avoidance decisions. While it does not explicitly mention Palestinians' digital rights, the contribution touches on the everyday women's communicative agency in contested territories within conservative cultures.

\section{Transnational Chronologic and Geographical Synapses}

The contributions in this thematic issue not only reconstruct and reflect on a turbulent chronological arc of 10 years since 2011, but they also go further to historicize social movement media across time and space and build transnational synapses across geographies. In her innovative contribution, Gretchen King (2021) historicizes the social movement media before and beyond the Arab Uprisings by comparing the Zapatistas and the Palestinian struggle to build networked and independent media as a tool to resist state power, capitalism, and colonialism effectively. The author develops a transnationally valid political economy framework that offers a promising heuristic model that can be adapted in other struggles for self-determination and dignity beyond the Arab Uprisings.

Similarly crossing geographies, Shiming $\mathrm{Hu}$ et al. (2021) offer an original perspective answering how Chinese media and foreign policy constructed the Arab Uprisings in its coverage. Taking a long-term reconstruction of media discourses through a comparative framing analysis of the Arab Uprisings in two influential Chinese media over 10 years, People's Daily (the official organ of the ruling Communist Party) and Caixin Net (a commercial paper), the contribution shows how the interest in the region declined over time. In line with research on foreign coverage, the article showed that the overall framing followed the strategic Chinese foreign policy towards the Arab region. However, frames differed according to media ownership as the private Caixin Net diverged from the official policy, nuancing what we know of how China views the Arab region.

\section{Conclusion}

As we are writing this introductory editorial to our thematic issue 10 years after the Arab Uprisings, the Arab region is still experiencing ripples of effect since the first uprising moment in 2010/2011: upcoming elections in Libya, upheavals in Sudan, and an ongoing civil war in Syria. It is therefore not easy to find one summarizing argument for such rich contributions that cover a vast region with different theoretical lenses and methods. Reflecting on 10 years of media and Arab Uprisings changes over an arc means uncertainty, not only for the livelihoods in the region but also the research results. The thematic issue cannot and does not want to offer definite answers because of the shifting and inherent instabilities. We still need answers on how media and journalism are relevant to the post-Arab Spring phase and beyond the massive disruptive processes around 2010/2011 and 2018-2021.

Revisiting media and the Arab Uprisings after 10 years encouraged critical-reflective articles that dared interdisciplinary modes of analysis, building connections to neighboring fields such as social psychology, political sciences, and urban studies. Several contributions underlined the transnational interconnected dynamics. This only proves how fertile the field of bringing Arab Uprisings and media and communication studies together can be beyond the classic linear transition paradigm. Paying attention to old and new media equally opens the door for more contextualized results that do not neglect the mainstream media such as TV and journalism. The broad range of themes in this thematic issue is proof of two things: that the upheavals and media in the Arab region need more systematic research and that the differentiated body of literature shows the possible research beyond the paths trodden so far.

\section{Conflict of Interests}

The authors declare no conflict of interest.

\section{Disclaimer}

The Arab-German Young Academy of Sciences and Humanities (AGYA) is supporting the thematic issue "Ten Years after the Arab Uprisings: Beyond Media and Liberation," edited by AGYA alumna Hanan Badr (Gulf University of Science and Technology, Kuwait) and AGYA member Lena-Maria Möller (Max Planck Institute for Comparative and International Private Law, Germany). AGYA is funded by the German Federal Ministry of Education and Research (BMBF). The authors remain solely responsible for the content and recommendations provided in this publication, which does not reflect the positions of AGYA or any of its funding partners. 


\section{References}

Badran, Y. (2021). Understanding emerging media: Voice, agency, and precarity in the post-2011 Arab mediasphere. Media and Communication, 9(4), 264-274.

Bassil, N., \& Kassem, N. (2021). The subtle dynamics of power struggles in Tunisia: Local media since the Arab Uprisings. Media and Communication, 9(4), 286-296.

de Vries Kedem, M., \& Majlaton, M. (2021). The voice of silence: Patterns of digital participation among Palestinian women in East Jerusalem. Media and Communication, 9(4), 309-319.

Elmouelhi, H., Meyer, M., Reda, R., \& Abdelhalim, A. (2021). Mediatizing slum relocation in Egypt: Between legitimization and stigmatization. Media and Communication, 9(4), 345-359.

Hu, S., Hou, W., \& Xu, J. (2021). How do chinese media frame Arab Uprisings: A content analysis. Media and Communication, 9(4), 331-344.

King, G. (2021). From Chiapas to Palestine: Historicizing social movement media before and beyond the Arab Uprisings. Media and Communication, 9(4), 320-330.

Kozman, C., Tabbara, R., \& Melki, J. (2021). The role of media and communication in reducing uncertainty during the Syria war. Media and Communication, 9(4), 297-308.

Leihs, N. (2021). A case study: Mada Masr-A progressive voice in Egypt and beyond. Media and Communication, 9(4), 275-285.

\section{About the Authors}

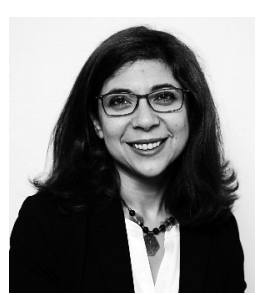

Hanan Badr is associate professor at the Department for Mass Communication and Media at the Gulf University of Science and Technology, Kuwait. Her work focuses on digital journalism, comparative media systems, and transformation. She held positions at Freie Universität Berlin, Cairo University, and Orient-Institut Beirut. She will start her chair for Public Spheres and Inequalities at Paris Lodron University of Salzburg, Austria.



Lena-Maria Möller is a scholar of comparative and Middle Eastern law affiliated with the Max Planck Institute for Comparative and International Private Law in Hamburg, Germany. Her research interests concern contemporary Middle Eastern and Islamic law, with a particular focus on Muslim family law and the GCC states, as well as comparative and private international law, and, most recently, law and popular culture in the Middle East. Lena-Maria Möller is a member and former co-president of the Arab-German Young Academy of Sciences and Humanities and serves as associate editor of the Arab Law Quarterly. 